\title{
Factors facilitating and hindering the intention to promote pulmonary rehabilitation for patients with COPD among respiratory therapists
}

This article was published in the following Dove Press journal: International Journal of COPD

II September 2017

Number of times this article has been viewed

\author{
Yun-Ju Chen' \\ Jun-Yu Fan ${ }^{2}$ \\ Su-Er Guo ${ }^{2-4}$ \\ Su-Lun Hwang 2,3 \\ Tsung-Ming Yang ${ }^{4}$
}

'Division of Respiratory Therapy, Chiayi Chang Gung Memorial Hospital, Chang Gung Medical Foundation, Chiayi, Taiwan, Republic of China; ${ }^{2}$ Graduate Institute of Nursing, College of Nursing, Chang Gung University of Science and Technology, Chiayi, Taiwan, Republic of China; ${ }^{3}$ Chronic Diseases and Health Promotion Research Centre, Chang Gung University of Science and Technology, Chiayi, Taiwan, Republic of China; ${ }^{4}$ Division of Pulmonary and Critical Care Medicine, Chiayi Chang Gung Memorial Hospital, Chang Gung Medical Foundation, Chiayi, Taiwan, Republic of China
Correspondence: Su-Er Guo Chronic Diseases and Health Promotion Research Centre, Chang Gung University of Science and Technology, 2 Sec W, jiapu road, Puzi City, Chiayi 61363,

Taiwan, Republic of China

Tel +886 53628800 ext 2617, 233।

Fax +886 53628866

Email sxg90huang@gmail.com
Purpose: Pulmonary rehabilitation (PR) is recognized as the chief non-pharmacologic management approach for patients with COPD, but is clinically under-utilized. In Taiwan, respiratory therapists (RTs) are one of the first-line health care providers who spend vast amounts of time with COPD patients in PR programs. To better enhance patients' knowledge of and participation in PR, it is necessary to understand how PR is viewed by RTs, as well as how these views influence their behavioral intentions toward promoting PR. This study applied the Theory of Planned Behavior (TPB) to investigate both the behavioral intentions and the influential factors surrounding PR in RTs.

Patients and methods: This cross-sectional study used structured self-administered questionnaires at a national symposium for RTs to collect data on their knowledge, attitudes, subjective norms, perceived behavioral controls, and behavioral intentions with regard to promoting PR. Multiple linear regression analysis was used to identify significant factors affecting the intended promotion of PR by RTs.

Results: The response rate after excluding respondents with incomplete data was $88.1 \%(n=379)$. A majority of the participants were college graduates, aged over 30 years, and women. The respective percentage scores derived from questionnaires gauging the knowledge, attitudes, subjective norms, self-efficacy, and behavioral intentions components of total PR scores were $63.12 \%$, $71.33 \%, 68.96 \%, 66.46 \%$, and $80.29 \%$. The factors significantly affecting RTs' intentions to suggest PR participation to COPD patients or encourage it were attitudes, subjective norms, and self-efficacy. The total model explained $22.5 \%$ of the variance in behavioral intentions.

Conclusion: The results of the study suggest that RTs strongly intend to promote PR, but are hindered by insufficient knowledge, attitudes, and self-efficacy with regard to it. Applying TPB provided insight into which factors can be addressed, and by whom. For example, enhancing RTs' self-efficacy can be achieved through PR training via school curricula, further regular continuing education and/or courses, and practical experience.

Keywords: behavioral intention, theory of planned behavior, exercise program, self-efficacy, respiratory therapist, COPD

\section{Introduction}

COPD is a leading cause of disability and death in middle-aged and elderly patients worldwide. It is characterized by dyspnea and inactivity, and results in an irreversible decline in lung function. ${ }^{1}$ The treatment goal is to provide patients with support, and assist them with self-management. ${ }^{2}$ The World Health Organization (WHO) projected that COPD would rise in rank from the fifth leading cause of death worldwide in 2002 
to the third in $2030 ;^{3}$ it is in fact already ranked fourth as of 2015. ${ }^{4}$ In Taiwan, COPD was the seventh leading cause of death in $2015 .^{5}$

The Global Initiative for Chronic Obstructive Lung Disease (GOLD) has recommended pulmonary rehabilitation (PR) as a standard treatment for patients with moderate to very severe COPD (stages $2-4) .{ }^{1}$ PR involves individualized therapy based on the patient's traits, and includes assessment, exercise training (sometimes involving specialized exercise therapists), psychological support, and health education. ${ }^{6}$ The aims of PR are to improve a patient's physical and psychological status by promoting healthy behavior, ${ }^{7}$ and randomized controlled trials ${ }^{8,9}$ and meta-analyses ${ }^{10}$ suggest that it is effective in improving activity intolerance, dyspnea, physical function, and quality of life. However, the rate of participation in PR programs among patients with COPD is low. A lack of accessibility to PR seems evident, in that a Canadian study ${ }^{11}$ found that only $1.2 \%$ of the COPD population investigated had participated in a PR program, and a Swiss study was even lower, at only $0.2 \% .^{12}$ In Taiwan, although the lack of accessibility contributes to it, a lack of awareness of the importance and potential benefits of PR on the part of many of the patients with COPD is a major factor in low PR participation.

Respiratory therapists (RTs) are one of the first-line licensed health care providers for patients with COPD, and they play an important role in patient evaluation, exercise prescription, and education with regards to PR in Taiwan. Because a key barrier to utilization of PR is a lack of awareness of PR programs and their health benefits in patients, ${ }^{13}$ RTs are in an excellent position to improve PR utilization. Therefore, understanding both the positive and negative factors influencing RTs' behavioral intention to promote participation by patients with COPD in PR, can identify where efforts to improve utilization would be best applied. One method of accomplishing this is applying the Theory of Planned Behavior (TPB).

TPB is based on Fishbein and Ajzen's ${ }^{14}$ Theory of Reasoned Action (TRA), and has been used frequently in research to understand the facilitators and hindrances of planned behaviors. The TPB states that an individual's behavioral intentions and behaviors are generated by the collective influence of attitudes toward behavior, subjective norms, and perceived level of behavioral control. The TRA holds that human behavior can be controlled through individual will, but Ajzen ${ }^{15}$ subsequently explained that some aspects of human behavior are dependent on external influences - elements of "perceived behavioral control" such as resources, time, money, and self-efficacy. The current study explored RTs' behavioral intentions to promote PR to patients with COPD, as well as the factors influencing them, based on the TPB. ${ }^{15}$

\section{Materials and methods Design and sample}

In this cross-sectional correlational study, data were collected at a national symposium for RTs via structured self-administered questionnaires. The study was approved by the Institutional Review Board of Chang Gung Medical Foundation (number 1037017C). Written informed consent was obtained from each participant, all of whom were certified practicing RTs. The total number of respondents was 383 , but four were missing data, so 379 participants comprised the sample. The sample size was sufficient to achieve $80 \%$ power to yield significant results, with a small effect size of $f^{2}=0.04$ and $\alpha=0.05 .^{16}$

\section{Instruments}

Several structured self-administered questionnaires were used to gather data on demographic characteristics and PR-related knowledge, attitudes, subjective norms, perceived behavioral control, and behavioral intentions. The validity of all instruments was tested by calculating the content validity index (CVI). The CVI is based on expert ratings of relevance, and is the most widely used index in quantitative studies. ${ }^{17}$ The CVI is defined as the proportion of items on an instrument rated 3 or 4 by all of the content experts. ${ }^{17}$ All questionnaires had at least acceptable internal consistency reliability (Cronbach's alpha ranged from $0.70-0.93$; acceptable reliability is considered to be $0.70-0.80$; good reliability is $0.80-0.90)^{18,19}$ and good content validity indices (CVIs ranged from 0.90-0.98; good validity is considered to be 0.80 or above).

\section{Knowledge of PR}

PR-related knowledge was examined using a six-item questionnaire developed by the research team based on previous PR studies (Appendix 1). ${ }^{11,20,21}$ Three items were multiple choice questions with several possible correct answers and 1 point scored for each correct answer chosen. The other three items were yes/no questions. Possible scores ranged from 0 to 16 , with higher scores indicating greater knowledge of PR. Using psychometric tests, a Cronbach's alpha value of 0.70 and a total CVI of 0.90 were considered to be estimates of reliability and validity, respectively.

\section{Attitudes toward PR}

The category attitude toward behavior is defined as the person's general feeling of favorableness or unfavorableness 
for the behavior. ${ }^{22}$ As in previous PR studies, ${ }^{21,23}$ a questionnaire was used to assess RTs' perceptions of the importance of PR (Appendix 2). It uses a five-point Likert scale, with the options 1 (disagree strongly), 2 (disagree), 3 (no response), 4 (agree), and 5 (agree strongly). A higher score indicates that the RT perceived PR programs to be more important. Cronbach's alpha for reliability was 0.70 and the total CVI was 0.92 .

\section{Subjective norms}

A subjective norm is defined as the social pressure an individual feels either for or against performing a behavior. ${ }^{15}$ Social pressure may be externally applied, or it may be internally applied as the perception of the individual that specific social entities are applying pressure regarding the behavior. ${ }^{22}$ A five-item questionnaire (Appendix 3) developed by the research team using the definition of subjective norm and a previous study ${ }^{18}$ was used to assess the subjective norms related to levels of agreement with promoting participation in PR programs, using a five-point Likert scale. Higher scores indicate more positive subjective norms with regard to patients participating in PR programs. Cronbach's alpha for reliability was 0.73 and the total CVI was 0.90 .

\section{Perceived behavioral control}

In the TPB, perceived behavioral control is defined as "an individual's perceived ease or difficulty of performing the particular behavior", ${ }^{15}$ and six items were used to assess it in the current study (Appendix 4). The TPB holds that self-efficacy is the most important component of perceived behavioral control. Self-efficacy is defined as a person's beliefs about his/her ability to persist with tasks, complete tasks, and reach goals. ${ }^{24}$ Self-efficacy beliefs include cognitive, motivational, affective, and selection processes. A questionnaire was used to assess the self-efficacy levels of RTs with regard to promoting the participation of COPD patients in PR programs. It consisted of four items, and the total possible score ranged from 0 to 100 , in which a higher score indicated greater self-efficacy. Another item was used to explore the effect of Taiwan's National Health Insurance (NHI) program on $\mathrm{PR}$, using a five-point Likert scale ranging from 1 (disagree strongly) to 5 (agree strongly). Higher scores indicated greater perceived effects of the NHI program on RTs' promotion of participation in PR programs. Time issue was the last item, using a five-point Likert scale ranging from 1 (disagree strongly) to 5 (agree strongly). Higher scores indicated having greater perceived time to encourage patients with COPD to participate in PR programs. Cronbach's alpha for reliability was 0.93 and the total CVI was 0.98 .

\section{Behavioral intentions}

A behavioral intention is defined as an individual's anticipated or planned future behavior, ${ }^{25}$ and incorporates motivation and the individual's expectations regarding the outcome of the behavior in a specific setting. In operational terms, it is the likelihood of the individual to act. ${ }^{14}$ The behavioral intentions questionnaire consisted of two items: "I intend to encourage patients to participate in pulmonary rehabilitation program." "I intend to recommend patients participate in pulmonary rehabilitation program" (Appendix 5). The total possible score ranged from 0 to 10 . A five-point Likert scale ranging from 1 (disagree strongly) to 5 (agree strongly) was used to assess the willingness of RTs to promote the participation of COPD patients in PR programs. A higher score represented more positive behavioral intentions with regard to PR promotion (ie, a higher likelihood of promoting PR). Cronbach's alpha for reliability was 0.80 and the total CVI was 0.98 .

\section{Statistical analyses}

Data analyses were performed using SPSS software version 22.0 (IBM Corporation, Armonk, NY, USA). The dataset was analyzed using both frequency distribution and descriptive statistics. One-way analyses of variance, independent $t$-tests, or Pearson's correlation coefficients were used to analyze the relationships between variables prior to any regression analyses. Multiple linear regression analysis was used to identify factors influencing the behavioral intentions of RTs with regard to promoting PR. A $p$-value of $<0.05$ (two-tailed) was considered statistically significant.

\section{Results}

The overall response rate was $89.1 \%$ (383/430 subjects), but four questionnaires were excluded due to missing data; thus, 379 valid questionnaires $(88.1 \%)$ were included in the analysis. The mean age of the respondents was 35.2 years. The vast majority $(89.2 \%)$ were female, $93.4 \%$ had completed a college degree, and $81.7 \%$ worked at a district hospital or medical center (Table 1). Almost $40 \%$ had never received a PR education course, $11.1 \%$ had received clinical PR training with practical experiences, and only $13.8 \%$ of participants had or has been working in a PR center (Table 1).

\section{Knowledge of PR and attitudes toward PR} The mean PR knowledge score is shown in Table 2. Only $21.9 \%$ of the participants understood the causes of exercise 
Table I Demographic and clinical characteristics of participants $(n=379)$

\begin{tabular}{|c|c|c|}
\hline Characteristics & $\mathbf{n}$ & $\%$ \\
\hline \multicolumn{3}{|l|}{ Gender } \\
\hline Male & 338 & 89.18 \\
\hline Female & 41 & 10.82 \\
\hline \multicolumn{3}{|l|}{ Age (years)* } \\
\hline$<30$ & 141 & 37.40 \\
\hline $30-40$ & 123 & 32.63 \\
\hline$>40$ & 113 & 29.97 \\
\hline \multicolumn{3}{|l|}{ Education level ${ }^{\$}$} \\
\hline Junior college & 25 & 6.61 \\
\hline College or university & 329 & 87.04 \\
\hline Master's degree and above & 24 & 6.35 \\
\hline \multicolumn{3}{|l|}{ Managerial positions ${ }^{\ddagger}$} \\
\hline Yes & 16 & 4.24 \\
\hline No & 361 & 95.76 \\
\hline \multicolumn{3}{|l|}{ Working years ${ }^{\S}$} \\
\hline$\leq 2$ & 86 & 23.43 \\
\hline $3-10$ & 142 & 38.69 \\
\hline$>10$ & 139 & 37.88 \\
\hline \multicolumn{3}{|l|}{ Working environment" } \\
\hline Medical center & 102 & 27.13 \\
\hline District hospital & 205 & 54.52 \\
\hline Regional hospital & 52 & 13.83 \\
\hline Home service & 17 & 4.52 \\
\hline \multicolumn{3}{|l|}{ PR education" } \\
\hline Yes & 230 & 60.85 \\
\hline No & 148 & 39.15 \\
\hline \multicolumn{3}{|l|}{ PR experience** } \\
\hline Yes & 52 & 13.76 \\
\hline No & 326 & 86.24 \\
\hline
\end{tabular}

Notes: Missing data $(\mathrm{n}): * 2,{ }^{\$}\left|,{ }^{\ddagger} 2,{ }^{\$}\right| 2, \| 3, \pi 1, * * 1$. आPR education: PR-related in-service education program.

Abbreviation: PR, pulmonary rehabilitation.

intolerance in COPD patients. While only $25.1 \%$ knew the definition of PR, $35.6 \%$ knew that the best phase for the implementation of PR in COPD patients was GOLD grade 2 (moderately severe COPD). The RTs with PR experience at a PR center showed a greater level of PR knowledge than

Table 2 Descriptive statistics of knowledge, attitude, subjective norms, and self-efficacy of promoting PR $(n=379)$

\begin{tabular}{lllll}
\hline Outcome & Mean & SD & $\begin{array}{l}\text { Possible } \\
\text { scores range }\end{array}$ & $\begin{array}{l}\text { Percentage of } \\
\text { total score }\end{array}$ \\
\hline Knowledge of $\mathrm{PR}^{*}$ & 10.10 & 2.05 & $0-16$ & $63.12 \%$ \\
${\text { Attitude toward } \mathrm{PR}^{\$}}$ & 32.10 & 3.92 & $0-45$ & $71.33 \%$ \\
Subjective norms & 17.24 & 2.76 & $0-25$ & $68.96 \%$ \\
Self-efficacy & 265.84 & 61.59 & $0-400$ & $66.46 \%$ \\
Behavioral intention" & 8.03 & 1.09 & $0-10$ & $80.29 \%$
\end{tabular}

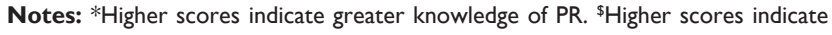
greater attitude toward PR. \#Higher scores indicate greater subjective norms of promoting PR. s Higher scores indicate greater confidence to provide PR. "Higher scores represent more positive behavioral intentions of RTs in PR promotion. "Percentage of the mean score to the total possible score.

Abbreviations: PR, pulmonary rehabilitation; RTs, respiratory therapists. those without $(10.92 \pm 1.94$ vs $9.93 \pm 2.10, p=0.009)$. The mean score for attitudes toward PR programs is also shown in Table 2. The vast majority (95.5\%) of participants agreed or strongly agreed that PR benefits COPD patients.

\section{PR promotion-related subjective norms and self-efficacy}

The mean score for subjective norms relating to the promotion of PR programs is shown in Table 2. RTs with PR experience in clinical practice had more positive subjective norms than those without such experience $(18.03 \pm 2.56$ vs $17.10 \pm 2.77, p=0.02$ ). There were significant differences in self-efficacy between RTs from different working environments, those who had undergone PR education vs those who had not, and those who had PR experience in clinical practice vs those who did not. RTs working in district hospitals or providing a home service had higher levels of self-efficacy than those who worked in other places. Moreover, RTs with PR experience in clinical practice had higher levels of selfefficacy than those without such experience (Table 3).

Table 3 Associations between characteristics of respiratory therapist and self-efficacy $(n=379)$

\begin{tabular}{llll}
\hline Variables & Self-efficacy & & \\
\cline { 2 - 4 } & M \pm SD & Flt & LSD \\
\hline Age (years) & & & \\
(1) $<30$ & $259.68 \pm 53.21$ & 1.35 & \\
(2) $30-40$ & $267.80 \pm 59.71$ & & \\
(3) $>40$ & $272.13 \pm 72.5$ I & & \\
Educational level & & & \\
(1) Junior college & $273.08 \pm 65.02$ & 1.78 & \\
(2) University & $263.82 \pm 62.29$ & & \\
(3) Master's degree and above & $287.08 \pm 44.70$ & & \\
Work years & & & \\
(1) $\leq 2$ & $260.41 \pm 46.22$ & 2.26 & \\
(2) $3-10$ & $259.37 \pm 63.69$ & & \\
(3) $>10$ & $273.84 \pm 67.72$ & & \\
Working environment & & & \\
(1) Medical center & $258.23 \pm 60.03$ & $3.82 *$ & (3) $>$ (1) \\
(2) District hospital & $265.25 \pm 62.77$ & & (3) $>$ (2) \\
(3) Regional hospital & $289.7 \pm 53.78$ & & (4) $>$ (1) \\
(4) Home care & $302.88 \pm 56.76$ & & (4) $>$ (2) \\
Managerial positions & & & \\
Yes & & & \\
No & $266.88 \pm 100.1$ & 0.04 & \\
Attended PR training courses & $266.60 \pm 59.64$ & & \\
Yes & & & \\
No & $273.51 \pm 58.26$ & $3.06 *$ & \\
PR experience & $253.83 \pm 65.04$ & & \\
Yes & & & \\
No & $293.90 \pm 47.63$ & $3.62 *$ & \\
\hline No & $261.14 \pm 62.38$ & & \\
\hline
\end{tabular}

Notes: F: One-way ANOVA test; $t$ : independent $t$-test; $* p<0.0$ I.

Abbreviations: ANOVA, analysis of variance; $M$, mean; PR, pulmonary rehabilitation; LSD, Fisher's least significant difference post hoc test; SD, standard deviation. 


\section{Factors associated with intentions to promote PR}

Bivariate analyses were performed with RTs' demographic characteristics, related clinical experiences, knowledge, attitude, subjective norms, perceived behavioral control, and behavioral intention. They revealed that RTs' intentions to promote PR were significantly associated with clinical factors including PR education courses $(t=-2.40$, $p=0.02)$, PR experiences $(t=-3.07, p=0.017)$, and PR-related knowledge $(r=0.12, p=0.02)$, attitudes $(r=0.17, p=0.001)$, and subjective norms $(r=0.43, p<0.001)$. In the perceived behavioral control component, there was no association between perceived NHI influence and behavioral intention $(r=0.09, p>0.05)$; only self-efficacy and time were associated with behavioral intention $(r=0.24, p<0.01 ; r=0.15$, $p<0.01$, respectively). However, there were no significant associations between related clinical experiences variables and RTs' intentions to promote PR in the multiple linear regression analysis (Table 4). The factors that significantly affected RTs' intentions to promote PR in the multiple linear regression analysis were attitude, subjective norms, and selfefficacy (Table 4 ). The total model explained $22.5 \%$ of the variance in behavioral intentions.

\section{Discussion}

PR programs are often implemented by RTs in Taiwan, so it is important to determine the levels of PR-related knowledge among RTs. In this study, the total percentage score for PRrelated knowledge was $63.12 \%$. Previously, Perez et $\mathrm{al}^{26}$ found that insufficient training can cause non-adherence to COPD therapy guidelines among clinicians. In the current study, the mean PR-related knowledge score of RTs with PR experience in clinical practice was greater than that of those without such experience ( $10.92 \pm 1.94$ vs $9.93 \pm 2.10)$, similar to the findings of Foster et al. ${ }^{27}$ In that study, a survey of adherence to COPD therapy guidelines among various physicians revealed that internal medicine physicians had a higher level of knowledge about COPD therapy guidelines

Table 4 Factors associated with behavioral intention of promoting pulmonary rehabilitation among respiratory therapists using multiple linear regression $(n=379)$

\begin{tabular}{|c|c|c|c|c|c|}
\hline Variables & $\beta$ & B & SE & $95 \% \mathrm{Cl}$ & $p$-value \\
\hline \multicolumn{6}{|l|}{ Age (years) } \\
\hline$<30$ vs $30-40$ & -0.039 & -0.132 & 0.222 & $-0.569 \sim 0.305$ & 0.553 \\
\hline$<30$ vs $>40$ & 0.089 & 0.308 & 0.303 & $-0.288 \sim 0.905$ & 0.310 \\
\hline \multicolumn{6}{|l|}{ Educational level } \\
\hline College or university vs junior college & 0.049 & 0.325 & 0.346 & $-0.355 \sim 1.006$ & 0.348 \\
\hline College or university vs Master's degree and above & -0.021 & -0.131 & 0.310 & $-0.742 \sim 0.479$ & 0.672 \\
\hline \multicolumn{6}{|l|}{ Working years } \\
\hline $3-10$ vs $\leq 2$ & -0.091 & -0.337 & 0.222 & $-0.773 \sim 0.099$ & 0.130 \\
\hline $3-10$ vs $>10$ & -0.095 & -0.311 & 0.236 & $-0.776 \sim 0.154$ & 0.190 \\
\hline \multicolumn{6}{|l|}{ Working environment } \\
\hline Medical center vs district hospital & 0.062 & 0.197 & 0.175 & $-0.147 \sim 0.54 \mid$ & 0.261 \\
\hline Medical center vs regional hospital & 0.016 & 0.086 & 0.293 & $-0.490 \sim 0.66 \mathrm{I}$ & 0.769 \\
\hline Medical center vs home service & 0.070 & 0.535 & 0.396 & $-0.244 \sim 1.313$ & 0.178 \\
\hline \multicolumn{6}{|l|}{ Managerial positions } \\
\hline Yes vs no & -0.026 & -0.199 & 0.403 & $-0.992 \sim 0.595$ & 0.623 \\
\hline \multicolumn{6}{|l|}{ PR training courses } \\
\hline Yes vs no & 0.032 & 0.103 & 0.159 & $-0.4 \mathrm{I} \sim 0.209$ & 0.516 \\
\hline \multicolumn{6}{|l|}{ PR experience } \\
\hline Yes vs no & 0.058 & 0.261 & 0.225 & $-0.182 \sim 0.704$ & 0.248 \\
\hline PR-related knowledge & 0.045 & 0.034 & 0.037 & $-0.038 \sim 0.105$ & 0.358 \\
\hline Attitude & 0.110 & 0.043 & 0.020 & $0.004 \sim 0.082$ & 0.029 \\
\hline Subjective norms & 0.371 & 0.214 & 0.030 & $0.156 \sim 0.272$ & 0.001 \\
\hline \multicolumn{6}{|l|}{ Perceived behavioral control } \\
\hline Self-efficacy & 0.125 & 0.003 & 0.001 & $0.00 \mathrm{I} \sim 0.006$ & 0.016 \\
\hline $\mathrm{NHI}$ & 0.061 & 0.096 & 0.078 & $-0.058 \sim 0.249$ & 0.222 \\
\hline Time & 0.037 & 0.06 & 0.085 & $-0.108 \sim 0.228$ & 0.484 \\
\hline Adjusted $R^{2}$ & 0.225 & & & & \\
\hline
\end{tabular}

Notes: $\beta$ : standardized coefficient; $B$ : unstandardized coefficient.

Abbreviations: PR, pulmonary rehabilitation; $\mathrm{NHI}$, National Health Insurance; SE, standard error. 
than other clinicians, due to their experience with COPD patients in clinical practice. This indicates that education can improve both adherence to COPD therapy guidelines and clinical care skills among physicians as well as RTs. Another study reported that physicians who do not renew their medical knowledge use antiquated treatments, resulting in non-adherence to therapy guidelines. ${ }^{28}$ Thus, continuing medical education is important for keeping medical personnel abreast of the current guidelines. One study reported that education alone had limited effects on behavior, but was a necessary first step toward changing it. ${ }^{29}$ Currently, PR is not incorporated as a major subject in school curricula for RTs in Taiwan. With regard to continued education after graduation, in Taiwan RTs acquire PR-related knowledge via in-service training from hospitals, or through symposia which are held irregularly by Taiwanese societies or associations. In the future, PR could be included as a major subject in curricula and ongoing education, in order to improve PR-related knowledge among RTs.

The mean total percentage score for attitudes toward PR was 71.33\%. Most RTs acknowledged the benefits of PR for patients with COPD, which is consistent with a cross-sectional study by Glaab et $\mathrm{al}^{30}$ in which only $1.7 \%$ of respirologists/pulmonologists did not believe that PR was beneficial for patients with COPD. However, that study disagreed with the results of Yawn and Wollan, ${ }^{31}$ who reported that only $3 \%$ of family medicine physicians and nursing practitioners acknowledged the benefits of PR, and $16 \%$ remained neutral. ${ }^{31}$

In the current study, RTs exhibited more positive intentions toward promoting the participation of patients with COPD in PR programs. This may be because RTs are the firstline health care providers for patients with COPD in Taiwan, and thus have the opportunity to observe the advantages of PR in such cases first-hand. In Taiwan, currently only physicians can prescribe PR therapy, but most do not prevent patients from self-referring. Therefore, we suggest that RTs could explain the benefits of PR to patients, thereby prompting them to request physicians to prescribe PR therapy.

\section{Facilitators and hindrances of the behavioral intention to promote PR}

We found that attitudes, subjective norms, and self-efficacy (perceived behavioral control) were the main factors affecting the intentions of RTs to promote the participation of patients with COPD in PR programs; these findings support the hypotheses of the TPB with regard to the prediction of intentions. There was a significant positive correlation between attitudes toward PR programs and behavioral intentions $(\beta=0.11, p=0.02)$, indicating that in RTs, more positive attitudes toward PR programs led to a greater propensity to promote PR programs, which is consistent with the TPB. ${ }^{15}$

Subjective norms and behavioral intentions to promote participation in $\mathrm{PR}$ programs are positively correlated ( $\beta=0.37, p<0.00001)$. According to the TPB, individuals expressing stronger subjective norms toward a specific behavior have stronger intentions to act. ${ }^{15}$ The most important factor affecting behavioral intentions in RTs in our study was subjective norms. The results indicated that RTs' behavioral intentions could be enhanced by increasing their subjective norms; in other words, increasing the pressure to promote PR through better support by their superiors and peers.

Self-efficacy is a determining factor in behavioral performance. ${ }^{32}$ A survey of obstacles related to adherence to COPD therapy guidelines among physicians revealed that low self-efficacy was an influential factor. ${ }^{26}$ Concordantly, our study also found a significantly positive association between self-efficacy and behavioral intentions $(\beta=0.13, p=0.008)$. A previous study reported that individuals with practical experience had higher self-efficacy with regard to implementing the related behavior; moreover, self-efficacy could be improved through simulation scenarios and experiential learning via models and practice. ${ }^{33,34}$ Similarly, we found that RTs with clinical PR experience or training had higher levels of self-efficacy. To increase self-efficacy, clinical training courses in PR including education courses and clinical practice training should be increased in the future.

External obstacles also affect adherence to clinical guidelines among health care providers. ${ }^{28}$ Medical insurance payment has been reported as a key factor influencing patients' willingness to adhere to treatment, ${ }^{35}$ and better medical insurance payment could also increase physicians' willingness to prescribe PR for patients with COPD. ${ }^{31,36}$ Notably however, medical insurance payment had no statistically significant influence on RTs' behavioral intentions in the present study, which may be related to the fixed salary of RTs, who derive no personal benefit from encouraging patients to participate in PR programs.

The model explains a relatively small $22.5 \%$ of the variance in behavioral intention. Ajzen $^{37}$ indicated that perceived behavioral control is a mix of two dimensions: self-efficacy and controllability. Controllability refers to the extent to which an individual believes that he or she has personal control over the performance of the behavior relative to control exerted by factors outside of the individual's control. Because we wanted to maximize our explanatory 
power and minimize measurement redundancy, ${ }^{38}$ we only examined self-efficacy, and not controllability. In addition, we did not examine incentivization (establishment of a reward system), an external factor with good potential for strengthening PR promotion. Future studies may benefit from further examination of self-efficacy, controllability, and other external variables such as the reward system.

\section{Strengths and limitations}

This study included a sample size sufficient to achieve $80 \%$ power to yield significant results. Together with the fairly high response rate $(89.1 \%)$ to the questionnaires, we could ensure a low level of bias.

There were several limitations to this study. Firstly, this study focused on behavioral intention, and there can be an intention-behavior gap that we could not account for with our methods. Secondly, the self-administered questionnaires were delivered during a national symposium of RTs, creating potential selection bias. Moreover, the participants may have discussed the contents of the questionnaires with others in the symposium, creating further potential for bias. Thirdly, the 379 participants in our study represented $18.56 \%$ of the total number of certified practicing RTs in Taiwan $(n=2,042)$, indicating that the sample was not random, and therefore not representative of the larger population. Lastly, while the reliability of the instruments has been fully tested, and they have good internal consistency, they are still being validated. Future studies may benefit from a randomized longitudinal design.

\section{Conclusion and implication}

In order to increase utilization of PR, health care providers should do more to promote its awareness and that of its health benefits among patients with COPD. However, previous studies mostly focus on physicians' referrals, and the lack of attention paid to other first-line health care providers' promotion of PR. This is the first survey using the TPB to investigate the facilitators and hindrances of RTs' behavioral intentions to promote PR. Promotion of participation in PR programs was associated with the attitudes, subjective norms, and self-efficacy of RTs, demonstrating the accuracy of the assumptions of the TPB. To enhance RTs' behavioral intentions to promote PR programs, positive attitudes, support from superiors and peers, and self-efficacy need to be improved.

Important clinical implications of this study include: 1) the superiors in hospital management should establish PR-related guidelines for RTs' roles and functions, in order to create more professional support and a social atmosphere; 2 ) the superiors can also set up a reward system as a strategy to improve PR promotion; 3) the superiors should give RTs enough time to inform patients of the benefits and effects of the PR program. PR training should form part of the school curriculum, and hospitals and professional associations should regularly offer continuing education and clinical practical sessions on PR for RTs. Clinical experience resulting from PR programs, or practical training in PR, may enhance RTs' self-efficacy, thereby increasing the likelihood of their promoting PR for patients with COPD, and thus improving the rate of utilization of PR programs among patients with COPD.

PR is an integrated, multidisciplinary, diversified care plan which involves collaboration between multiple teams. In the current study, we only focused on RTs - however, future research could explore this issue in the context of other medical professionals, such as physicians or nurses or physical therapists. Furthermore, to increase the promotion of PR, qualitative research could be undertaken in an effort to better understand the PR-related experiences of RTs, and the barriers to promoting it.

\section{Acknowledgments}

The authors would like to thank all the participants in this study. The study was supported by grants from the Chang Gung Medical Foundation (CMRPF6C0071, CMRPF6C0072, CMRPG6E0101) and the Ministry of Science and Technology, Taiwan (MOST103-2410-H-255002-MY3).

\section{Author contributions}

YJC and SEG substantially contributed to conception and design, and data collection. YJC, SEG, JYF, SLH, and TMY contributed toward data analysis, drafting and critically revising the paper. All authors contributed toward data analysis, drafting and critically revising the paper and agree to be accountable for all aspects of the work.

\section{Disclosure}

The authors report no conflicts of interest in this work.

\section{References}

1. Vestbo J, Hurd SS, Agustí AG, et al. Global strategy for the diagnosis, management, and prevention of chronic obstructive pulmonary disease: GOLD executive summary. Am J Respir Crit Care Med. 2013;187(4) 347-365.

2. Nici L, Donner C, Wouters E, et al. American Thoracic Society/ European Respiratory Society statement on pulmonary rehabilitation Am J Respir Crit Care Med. 2006;173(12):1390-1413. 
3. who.int [homepage on the Internet]. Burden of COPD. World Health Organization; 2016. Available from: http://www.who.int/respiratory/ copd/burden/en/. Accessed August 3, 2017.

4. who.int [homepage on the Internet]. The top 10 causes of death. World Health Organization; 2016. Available from: http://www.who.int/ mediacentre/factsheets/fs310/en/. Accessed August 3, 2017.

5. mohw.gov.tw [homepage on the Internet]. 2015 death causes in statistics. Ministry of Health and Welfare Taiwan (MOHW), Executive Yuan; 2016. Available from: http://www.mohw.gov.tw/ CHT/DOS/Statistic.aspx?f_list_no $=312 \&$ fod_list_no $=6201$. Accessed August 3, 2017.

6. Carlin BW. Pulmonary rehabilitation: a focus on COPD in primary care. Postgrad Med. 2009;121(6):140-147.

7. Spruit MA, Singh SJ, Garvey C, et al. An official American Thoracic Society/European Respiratory Society statement: key concepts and advances in pulmonary rehabilitation. Am J Respir Crit Care Med. 2013; 188(8):e13-e64.

8. Puhan MA, Gimeno-Santos E, Scharplatz M, Troosters T, Walters EH, Steurer J. Pulmonary rehabilitation following exacerbations of chronic obstructive pulmonary disease. Cochrane Database Syst Rev. 2011;(10):CD005305.

9. Corhay JL, Dang DN, Van Cauwenberge H, Louis R. Pulmonary rehabilitation and COPD: providing patients a good environment for optimizing therapy. Int J Chron Obstruct Pulmon Dis. 2014;9: 27-39.

10. McCarthy B, Casey D, Devane D, Murphy K, Murphy E, Lacasse Y. Pulmonary rehabilitation for chronic obstructive pulmonary disease. Cochrane Database Syst Rev. 2015;(2):CD003793.

11. Brooks D, Sottana R, Bell B, et al. Characterization of pulmonary rehabilitation programs in Canada in 2005. Can Respir J. 2007;14(2): 87-92.

12. Wadell K, Janaudis Ferreira T, Arne M, Lisspers K, Ställberg B, Emtner M. Hospital-based pulmonary rehabilitation in patients with COPD in Sweden - a national survey. Respir Med. 2013;107: $1195-1200$

13. Johnston K, Grimmer-Somers K, Young M, Antic R, Frith P. Which chronic obstructive pulmonary disease care recommendations have low implementation and why? A pilot study. BMC Res Notes. 2012; 5:652.

14. Fishbein M, Ajzen I. Belief, attitude, intention, and behavior: An introduction to theory and research. Boston: Addision-Wesley; 1975.

15. Ajzen I. The theory of planned behavior. Organ Behav Hum Decis Process. 1991;50(2):179-211.

16. Cohen J. Statistical Power Analysis for the Behavioral Sciences. Hillsdale, NJ: Lawrence Erlbaum Associates; 1988:467-530.

17. Polit DF, Beck CT. The content validity index: are you sure you know what's being reported? critique and recommendations. Res Nurs Health. 2006;29(5):489-497.

18. Kline P. Psychometric theory and method. The handbook of psychological testing (2nd ed.). London: Routledge; 2000:13.

19. DeVellis RF. Applied Social Research Methods. Scale development: Theory and applications. Los Angeles: Sage; 2012:109-110.

20. Rutschmann OT, Janssens JP, Vermeulen B, Sarasin FP. Knowledge of guidelines for the management of COPD: a survey of primary care physician. Respir Med. 2004;98(10):932-937.
21. van der Wees PJ, Zagers CA, de Die SE, Hendriks EJ, Nijhuis-van der Sanden, de Bie RA. Development a questionnaire to identify perceived barriers for implementing the Dutch physical therapy COPD clinical practice guideline. BMC Health Serv Res. 2013;13:159.

22. Ajzen I, Fishbein M. Understanding attitudes and predicting social behavior. New Jersey: Prentice-Hall; 1980.

23. Nwosu AC, Bayly JL, Gaunt KE, Mayland CR. Lung cancer and rehabilitation - what are the barriers? Results of a questionnaire survey and the development of regional lung cancer rehabilitation standards and guidelines. Support Care Cancer. 2012;20(12):3247-3254.

24. Ormrod JE. Learning and Cognitive Processes. Educational Psychology: Developing Learners. 5th ed. Upper Saddle River, NJ: Pearson/ Merrill Prentice Hall; 2006:199.

25. Swan J. Disconfirmation of expectations and satisfaction with a retail service. Journal of Retailing. 1981;57(3):49-66.

26. Perez X, Wisnivesky JP, Lurslurchachai L, Kleinman LC, Kronish IM. Barriers to adherence to COPD guidelines among primary care providers. Respir Med. 2012;106(3):374-381.

27. Foster JA, Yawn BP, Maziar A, Jenkins T, Rennard SI, Casebeer L. Enhancing COPD management in primary care settings. Med Gen Med. 2007;9(3):24.

28. Cabana MD, Rand CS, Powe NR, et al. Why don't physicians follow clinical practice guidelines? A framework for improvement. JAMA. 1999;282(15):1458-1465.

29. Scott SD, Albrecht L, O'Leary K, et al. Systematic review of knowledge translation strategies in the allied health professions. Implement Sci. 2012;7:70.

30. Glaab T, Vogelmeier C, Hellmann A, Buhl R. Guideline-based survey of outpatient COPD management by pulmonary specialists in Germany. Int J Chron Obstruct Pulmon Dis. 2012;7:101-108.

31. Yawn BP, Wollan PC. Knowledge and attitudes of family physicians coming to COPD continuing medical education. Int J Chron Obstruct Pulmon Dis. 2008;3(2):311-317.

32. Bandura A. Self-efficacy. In: Howard F, editor. Encyclopedia of Mental Health. Vol. 4. San Diego: Academic Press; 1998:71-81.

33. Chiang LC, Kuo YW, Lin CJ. [A concept analysis of self-efficacy]. Hu Li Za Zhi. 2004;51(2):67-72. Chinese.

34. Fejzic J, Barker M. Implementing simulated learning modules to improve students' pharmacy practice skills and professionalism. Pharm Pract (Granada). 2015;13(3):583-590.

35. Menezes AM, Landis SH, Han MK, et al. Continuing to confront COPD international surveys: comparison of patient and physician perceptions about COPD risk and management. Int J Chron Obstruct Pulmon Dis. 2015;10:159-172.

36. Huang CM. The influence of pharmaceutical marketing strategy $4 P$ and health insurance in willing of usable medicine: A case study in the Kaohsiung area [master's thesis]. Kaohsiung City, TW: I-Shou University; 2010.

37. Ajzen I. Perceived behavioral control, self-efficacy, locus of control, and the theory of planned behavior. J Appl Soc Psychol. 2002;32(4): $665-683$.

38. Rhodes RE, Courneya KS. Self-efficacy, controllability and intention in the theory of planned behavior: measurement redundancy or causal independence? Psychology \& Health. 2003;18(1):79-91.
International Journal of COPD

\section{Publish your work in this journal}

The International Journal of COPD is an international, peer-reviewed journal of therapeutics and pharmacology focusing on concise rapid reporting of clinical studies and reviews in COPD. Special focus is given to the pathophysiological processes underlying the disease, intervention programs, patient focused education, and self management protocols.

\section{Dovepress}

This journal is indexed on PubMed Central, MedLine and CAS. The manuscript management system is completely online and includes a very quick and fair peer-review system, which is all easy to use. Visit http://www.dovepress.com/testimonials.php to read real quotes from published authors. 